\title{
Supporting pedagogical change through teacher development
}

\author{
Joy Murray \\ New South Wales Department of Education and Training, 3a Smalls Road, Ryde, NSW 2112, \\ Australia.jomurray@ozemail.com.au
}

Keywords: teacher development, pedagogical change, computer technology, flexible delivery

\begin{abstract}
This paper describes an innovative teacher professional development programme, Technology in Learning and Teaching (TILT) developed in Australia by the New South Wales Department of Education and Training. It describes the programme itself which is flexible enough to satisfy individual needs while at the same time providing an introduction to, and practice in, specific skills. The paper outlines the collaborative process of conceptualisation, development, piloting, evaluation and implementation across the state. This collaborative process is reflected in the programme itself and provides its philosophical base. The TILT programme aims to motivate and support teachers as they develop new skills, to give them the confidence and enthusiasm to go on learning after the programme has finished. The paper concludes with an examination of the programme's achievements and implications for further development.
\end{abstract}

\section{INTRODUCTION}

A change programme is more than its booklets, equipment, video and audio cassettes and disks designed to convey some identified content. The concepts important to writers, audio and video makers rely on more than words and images to convey their message. In workshops learning depends on a facilitator's creation of an atmosphere of trust, respect, enthusiasm and excitement. An examination of hardware, software and courseware will not convey what the materials mean to participants in any useful sense. They will have different meanings to different people in different contexts 
depending on their current knowledge, skills and disposition and their individual learning needs. A change programme is far more than the sum of the parts.

Learning is built on the relationships which unfold through collegial support networks and in communication with facilitators who provide a context in which the learning can occur. As Stacey says, "successful human organisation cannot be the realisation of some shared intention formed well ahead of action. Instead, success has to be the discovery of patterns that emerge through actions we take in response to the changing agendas of issues we identify" (Stacey 1992 in Fullan 1993). An effective change programme therefore needs to provide opportunities for the building of relationships through communication and through working together on projects of mutual benefit. A well designed programme will exemplify Banathy's (1988) heuristic system types, systems which he describes as "open to and co-evolving with their environments", fluid enough, and responsive enough, to allow for changes to take place. It will take a learning systems approach to development which, according to Bawden (1994), "allows a series of vital insights into the way organisations deal with the demands of their ever-changing environments - indeed it supports the view that successful organisations - as communities-of-learners - learn to coevolve along with their environments, rather than simply reacting to the environmental changes forced upon them."

2.

DEVELOPMENT AND IMPLEMENTATION OF A CHANGE PROGRAMME

\subsection{Technology in Learning and Teaching (TILT)}

The TILT programme was developed in $1995 / 6$ in response to a NSW State Government promise to provide training in the classroom use of computer and information technology (CIT) for teachers who were not already using technology in the classroom. TILT is designed for teachers of Kindergarten to Year 12 and across all subject areas. In NSW the TILT programme has been provided for 15000 teachers across the state, which is approximately one third of every school's full time teaching staff.

TILT deals with the development of teacher skills in the use of CIT; it is also a programme about extending teacher choices for what and how things happen in classrooms. It examines a range of hardware and software applicable for a range of age groups and learning areas providing transferable skills and an understanding of underlying concepts. It includes suggestions on how to incorporate computer technology into classroom life 
and support for teachers in using CIT for administrative and research purposes.

The aim of TILT is to give teachers the confidence and skills to begin using computer technology for administrative purposes, professional purposes (such as research and lesson preparation) and in the classroom. More importantly it is hoped that TILT will give teachers the enthusiasm to continue learning about and with CIT. Behind this is the view that the use of computers and information technology will support a paradigm shift in education from objective to constructed knowledge; from teacher centred to learner centred classrooms; from teaching and instruction to learning; from time and place bound to flexible access (e.g. Papert 1993; Dwyer 1995).

\subsection{The context}

TILT was developed following the Labor Party's success in the 1995 NSW state election. It was part of an overall whole of government strategy to upgrade technological infrastructure and make the increasing use of ICT a priority. In particular TILT was part of the government's Computers in Schools Policy which included: providing all schools with an Internet machine and if necessary an additional telephone line; linking all schools to the Internet; providing advice on the use of CIT in the primary school classroom and in each secondary school learning area; the rollout of computers to schools to achieve a ratio of at least one computer to 14 students; and the creation of a Department of Education and Training website to include online curriculum based activities for students as well as information and on line development programmes for teachers.

The election promise was to provide a 30 hour technology training course to 'kick start' teachers who were not already using technology in the classroom. The developers of TILT, aware of research around what makes a good teacher development programme and what constitutes good teaching with and about computer technology, had therefore to satisfy the needs of government as well as their beliefs about good professional development. Each teacher was to have 2 days relief from face-to-face teaching (later to become 3 days), the Internet was to feature prominently and teachers were to be introduced to touch typing. The challenge was to convey enough enthusiasm to make a 30 hour course last a life time.

\subsection{Development history: consulting with stakeholders}

A teacher development programme is implicitly underpinned by the principles which have guided the programme's development process. A programme which respects the learner begins with the developers' respect for a broad range of expertise. A programme which addresses the learner as 
colleague is developed between colleagues. A programme which allows for diversity (multiple entry points and multiple pathways) is developed in an atmosphere which allows for creative ideas to flourish. Programme and programme development implicate each other.

The development of TILT began with consultation with representatives of stakeholder groups and the involvement of a wide range of people bringing a broad knowledge base to the course development. In all about 30 people attended a two day planning meeting in July 1995. The meeting produced a set of principles which would underpin the programme (flexible delivery; school based learning; individual learning pathways; learning partners; negotiated assessment), a set of desired outcomes for teachers and for students, and a map of the content to be covered. To a great extent the processes employed in this 2 day meeting were reflected in the product. The set of principles respected the learner, the outcomes for teachers and students supported the learner and the content to be covered both satisfied the needs of government and allowed for diversity of participant needs and interests. Systems theory referred to above (Benathy 1988; Bawden 1994) provided the framework for a non-hierarchical networked structure in which the programme would operate.

Concurrently work was continuing on an evaluation strategy and a Principals' Briefing package which was to inform principals of the programme, give advice on identification of participants and ways in which participants could be supported.

\subsection{Implementation: the importance of participant feedback}

The programme that emerged from the above process consists of 6 one hour interactive satellite broadcasts (now videos), 6 small group hands on workshops and 3 days' in-school follow up activities (see below). The first satellite broadcast and the first 2 workshops were piloted in semester 2 , 1995 with approximately 130 participants from 66 schools in 2 metropolitan and 2 rural regions. These pilot workshops were 3 hours long rather than two hours, the third hour being a participant feedback session. At the same time a base data survey was trialled as part of the evaluation strategy. This has been reissued each semester. It seeks EEO statistics and information on previous experience with, and use of, computer technology both in the classroom and at home.

Towards the end of 1995 the TILT facilitators, together with a small number of participants, principals and representatives from the original working group came together for 2 days to evaluate the pilot. This meeting was also attended by the broadcast producers and workshop material writers. Changes were made to the content of the materials and the sequence of 
components. The original 2 days relief was raised to 3 days for each participating teacher in response to a NSW Teachers Federation agreement.

TILT was trialed in semester 11996 with approximately 400 participants from the same 66 schools. The 5 remaining satellite broadcasts were developed and broadcast at two to three week intervals throughout the semester. Course materials were written for the remaining 4 workshops. Meanwhile hardware and software was purchased to support implementation. The Principals' Briefing interactive satellite broadcast was trialed together with a support document. At the end of semester 1 a further feedback meeting was held and further adjustments made to materials, sequence and structure.

In semester 2 the participant group was increased to approximately 800 teachers in 16 districts. New facilitators were trained by the TILT team and the semester 1 facilitators. The training was also attended by district Technology Advisers and Training and Development/Curriculum Coordinators to facilitate team building and district planning. In 1997 the programme was implemented in all 40 NSW school districts. Changes continue to be made in response to participant comments invited at the end of each semester. Evaluation results and any changes made as a consequence are conveyed to schools each semester in the TILTed Newsletter. It is considered important that facilitators and participants know that their comments are taken seriously and acted on wherever possible.

\section{MOTIVATING AND SUPPORTING TEACHERS AS THEY DEVELOP NEW SKILLS}

\subsection{Meeting participant needs}

The TILT programme is based on the assumption that teachers have different needs at different times and bring different skills and knowledge to any learning situation. Even with a selection criterion of teachers who are not currently using technology in the classroom it is evident that there is a whole range of expertise in any group of participants. TILT takes this into account and provides a range of activities from which to choose. Teachers can access the materials in their own time, progress at their own pace and work with friends and colleagues from their own school or across schools. In all of this they are supported by a trained facilitator.

The TILT folder contains 6 booklets, a journal/workbook, 6 audio cassettes holding recordings of the readings (paper copy is included in the booklets) and CDROM with support activities and sample software. 
Participants either work with the facilitator through the workshop material or negotiate a different activity based on their own needs and abilities.

Each booklet includes: a basic workshop (presented by the facilitator) with prompts for reflection; suggested follow up activities; suggested classroom activities; 2-3 self paced extension activities (designed for participants already familiar with the basic workshop who choose to follow an extension activity in workshop time); and readings. Feedback from participants indicates that the TILT folders are well received; the many cartoons by Mark David are particularly appreciated. The inclusion of self paced extension activities makes the folders a valued resource.

The six satellite broadcasts which accompany the workshop materials were shown in semesters 1 and 2 1996, 2-3 weeks apart. In 1997 the broadcasts were provided on video for loan to schools. In semester 11997 the broadcasts were also shown as 30 minute programmes free to air on the SBS national series tvED. The satellite broadcasts provide examples from a range of schools where teachers and students are using technology in the classroom. They each feature a studio panel of teacher, community, business or academic experts who address issues associated with the focus of the programme. In addition 2 TILT participants (one primary, one secondary) are visited as they progress through the workshops, they comment on changes to their administration practices; they and their students comment on changes in teaching practice. The satellite broadcasts allowed space for addressing government priorities as well as priorities identified by the development team.

The broadcast is followed within 2 weeks by a hands on workshop. Workshops are conducted locally either in participants' own schools or at a nearby school or technology centre in small groups of between 10 and 12 participants. The workshop begins with afternoon tea and a discussion of issues raised by the broadcast and the sharing of between workshop activities. Most of the rest of the 2 hours is devoted to hands-on work at the computer, or to using other items of hardware, such as a digital camera. The emphasis is on creating a non threatening learning environment in which participants are able to work at their own pace and gain whatever support they need.

Follow up is conducted in the participant's own school at any time throughout the semester. Each participant is allocated 3 days casual relief to be spent, in consultation with the school principal and according to the participant's learning needs. The time can be used to exchange visits with other teachers in their own or neighbouring schools; release another teacher to team teach with the participant; take time out to explore software or hardware; practise skills learned in the workshop; prepare a unit of work; participate in an additional daytime workshop offered by the facilitator or 
whatever else participants choose in order to follow up on their learning. Participants may invite the facilitator to visit them in their school to assist in follow up work. This could be a one to one session or a group of teachers may have common needs. It is this in-school follow up feature of TILT that gives the programme such flexibility, allowing for multiple entry points, pathways, learning needs and styles.

\subsection{TILT facilitators}

Facilitators are classroom teachers chosen for their people skills, technological know-how and enthusiastic classroom use of computer and information technologies. Their role is to impart the enthusiasm and confidence needed by participants to continue learning long after the programme has finished.

Facilitators work for a semester across a school district. Each full time facilitator is allocated 70 participants. The participants are organised into workshop groups of approximately 10 people. The role of the facilitator is to conduct workshops, and provide individual or small group support by request as participants take up their 3 relief days to extend their learning.

New facilitators receive two three-day residential training programmes conducted by experienced facilitators and members of the TILT team. The training programmes are approximately six weeks apart to allow time for facilitators to work with participants before coming back together again to discuss issues arising from experience. As part of their training facilitators participate in sessions on presentation skills, adult learning and reflective journal writing. Guest speakers like Toni Downes (1997) and Barbara Lepani (1993) address global perspectives opening discussion around economic, political, cultural, social and equity issues.

Each facilitator has the use of a TILT kit containing: music keyboards, concept keyboards, digital cameras, computer controlled lego kit, scanner, video camera, light projection equipment and an extensive range of software, all of which is available for loan to participants. Two laptop computers are also provided, one for use by the facilitator and one for lending out to participants.

Most facilitators are provided with a station wagon for travel around the district. In country districts these vehicles cover hundreds of kilometres each week, as facilitators travel to isolated schools to provide workshops and inschool follow up support.

\subsection{Assessment}

Certificates are awarded to TILT graduates provided they have: attended all workshops (or 5 out of 6 with a negotiated equivalent workshop activity 
for the sixth if necessary); and spent 3 relief days engaged in TILT related activities negotiated with, and supported by, the facilitator, or 2 relief days with an equivalent period of time spent in TILT related activities out of school hours if necessary. Districts hold certificate presentation ceremonies as a way of celebrating completion of the programme and congratulating graduates. TILT certificates have currency at several universities where participants may gain accreditation towards a Masters programme.

\section{CONCLUSION}

\subsection{What have we achieved?}

It would seem that TILT has satisfied the needs of government. In 1998 it was Highly Commended by the NSW Premier in the Premier's Public Sector Awards. It seems also to have satisfied the needs of participants: 97\% of respondents to the 1997 evaluation affirmed the high quality of their TILT facilitator; $81 \%$ commented that the programme was 'well organised', 'thorough' and 'professional'; and $74 \%$ commented on the 'excellent follow-up support'. The vast majority reported an increased confidence and a growing use of CIT both for professional and classroom purposes. Changes are occurring in teacher administration and in classroom uses of CIT. A 1998 survey of 402 TILT graduates (1996-1998) across all districts and types of schools revealed that $85 \%$ of respondents were now 'using CIT for administrative purposes' at least once a month (60\% at least once a week). More importantly $80 \%$ of respondents indicated that their students were now using 'keyboarding skills' and 'technology to enhance learning' at least once a month and the majority of participants reported that the TILT programme had assisted them to support students in their use of word processing and selected software packages. Given TILT's aim and target audience this is greatly encouraging. But has TILT in any way supported a paradigm shift in education?

Firstly, any programme can only ever be an invitation to change. It can expand options for classroom practice. For those who already support learner centred classrooms TILT offers additional skills in an already familiar context. For others like the teacher who said that TILT had opened up 'a whole new world' and that she was now, 'endeavouring to provide the same enlightenment' for her students, it provides a model for a learner centred process and a catalyst for other changes. In this sense TILT can be said to support a paradigm shift. It's strength is in its concern for individual needs, the fact that it takes seriously the knowledge teachers bring to the task, their interests and learning preferences; and it asks for and takes seriously comments on the content and process. Teachers take the feel of 
this with them (and their written comments consistently show this) but are not asked to explicate the parts that make up this particular whole. Secondly although TILT alone will not bring about system wide changes in teaching and learning TILT is just one of a range of programmes for teachers, many of which challenge fundamental beliefs about learning and take teachers through a process that does require discussion of, and reflection on, the parts and the whole.

\subsection{What next?}

TILT's context is one of changing technology, increasing complexity of the teaching task, and debate about valued knowledge and how it should be packaged and measured. Societies need teachers who can knowledgeably join in the debate and who are willing to continue learning throughout their careers. Requests for follow up programmes indicate that TILT facilitators have succeeded in conveying the enthusiasm and excitement needed for teachers to continue learning. TILT facilitators have deservedly gained the respect and trust of their students. They and we are well placed to work with teachers and school principals to build on these gains. We have already begun the process of consultation. The next four year plan will address: literacy and technology; information skills; values in technology and learning; it will provide school leaders with the knowledge and skills to address whole school planning for continuity in learning with CIT; it will provide an online forum for debate.

For the vast majority of participants TILT has done what it set out to do. The programmes that follow, that build on the skills and invite debate and reflection will be crucial in assisting all of us to understand how we can provide better learning environments for our students.

\section{REFERENCES}

Banathy, B. H. (1988) Matching design methods to system type. Systems Research 5(1) 2734.

Bawden, R. (1994) Learning to Become a More Effective Organisation: A Critical Systems Approach. University of Western Sydney, Hawkesbury: Hynwest (Consulting) Pty Ltd.

Downes, T. (1997) A matter of equity: Computers in Australian homes. Australian Educational Computing 12(1) 7-13.

Dwyer, D. (1995) Finding the future in the past: Readying schools for the 21 st century. Proceedings of the Australian Computers in Education Conference. Perth, Western Australia.

Fullan, M. (1993) Change Forces: Probing the Depths of Educational Reform. London: The Falmer Press.

Lepani, B. (1993) The Learning Revolution. Keynote address, The Learning Conference, Department of School Education. Sydney, 16 July 1993. 
Papert, S. (1993) The Children's Machine: Rethinking School in the Age of the Computer. New York: Basic Books.

\section{BIOGRAPHY}

Joy Murray is a Senior Project Officer (Training and Development) with the New South Wales Department of Education and Training. Since 1995 she has been responsible for the teacher development component of the State Government's Computers in Schools Policy. Much of her previous work has been in the development and implementation of Literacy programmes at national and state level. In partnership with representatives from six universities in four states she has recently completed a two year study of literacies and technologies in education for the Commonwealth Government. 